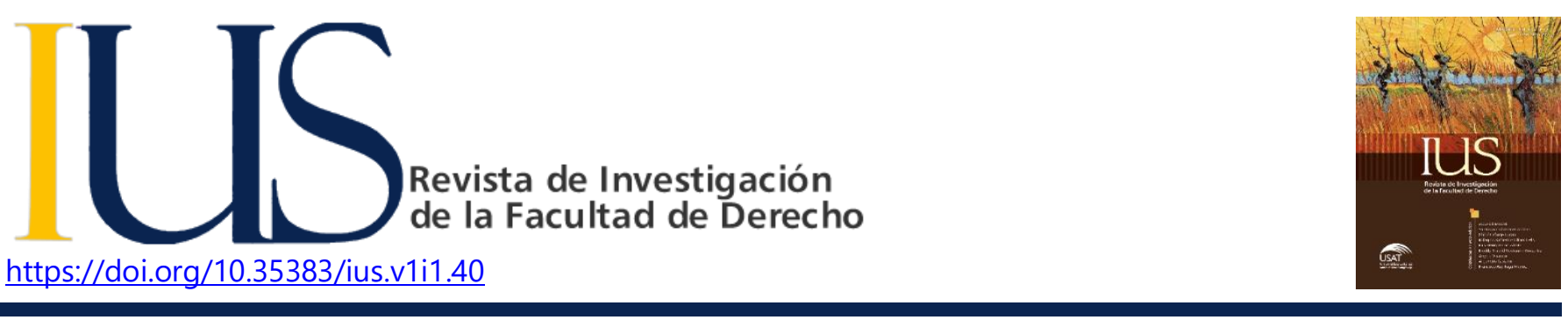

\title{
MANUEL PARDO Y EL DERECHO. LAS IDEAS JURÍDICAS DEL PRIMER PRESIDENTE CIVIL Freddy Ronald Centurión González ${ }^{1}$
}

\begin{tabular}{ll}
\hline INFORMACIÓN DEL ARTíCULO & RESUMEN \\
\hline Historia del artículo: & Manuel Pardo y Lavalle fue el primer Presidente Constitucional del Perú \\
Recibido el 1 de octubre de 2018 & que no provenía de las filas del ejército. No sólo fue el fundador del \\
Aceptado el 19 de marzo de 2019 & primer partido político peruano, el Partido Civil, sino que fue un \\
& ideólogo con una visión del país que aspiraba a concretar en el \\
\hline Palabras claves: & Gobierno. En años recientes se ha analizado ampliamente el significado \\
Historia de las ideas políticas & en la historia política peruana del ideario de Pardo, pero no se ha \\
Historia del Derecho peruano & examinado en detalle la visión jurídica que formaba parte del proyecto \\
Historia de la República & del fundador del civilismo. Buscamos, con este trabajo, ofrecer una \\
Partido Civil & aproximación a tal faceta.
\end{tabular}

The law positions of the first civil president of Peru: The Manuel Pardo case

\section{ABSTRACT}

\section{Keywords:}

History of political ideas History of Peruvian Law History of the Republic Civil Party

\begin{abstract}
Manuel Pardo y Lavalle was the first Constitutional President of Peru that didn't come from the ranks of the army. Not only he was the founder of the first Peruvian political party, the Civil Party, but he also was an ideologist with a vision of the country, which he aspired to concretize in the Government. In recent years the significance of Pardo's ideology in Peruvian political history has been widely analyzed, but the legal vision that was part of the project of the founder of the civilismo has not been examined in detail. We seek with this paper, to offer an approximation to this facet.
\end{abstract}

\section{INTRODUCCIÓN}

En la segunda mitad del siglo XIX, Manuel Pardo y Lavalle encarnó un pensamiento distinto, con el cual, irrumpió en el Perú decimonónico un nuevo concepto del Estado y de la sociedad, un concepto que iba más allá de los horizontes del caudillismo enraizado desde la Independencia. Personaje fascinante y controvertido, Pardo fue el fundador y líder del primer partido político en el Perú, el

\footnotetext{
${ }^{1}$ Maestrante en Derecho Constitucional y Gobernabilidad por la Universidad Nacional Pedro Ruiz Gallo, Docente de Historia del Derecho, Derecho Romano y Derecho Constitucional en la Facultad de Derecho de la USAT Email: fcenturion@usat.edu.pe
} 
Partido Civil, un partido que promovía un modelo que, en base a la laboriosidad y a la ética del trabajo, impulsaba una democratización del juego político hasta entonces inédita. Su acción no se limitó a buscar la modernización nacional en lo económico y técnico, sino también en la organización del Estado y la defensa de los derechos civiles. En tal sentido, a más de ciento ochenta años del nacimiento de Pardo, resulta interesante hacer una revisión de las ideas que el primer Presidente civil del Perú, quizá una de las mentes más lúcidas y visionarias de nuestra historia republicana, albergaba sobre el derecho y su aplicación práctica.

\section{UNA TRAYECTORIA RÁPIDA, BRILLANTE Y TRÁGICA}

Manuel Justo Pardo y Lavalle nació en Lima en agosto de 1834 , y fue asesinado, cuarenta y cuatro años después, en noviembre de 1878 , ad portas de la tragedia nacional de 1879 . Tuvo una trayectoria vital intensa y agitada en una etapa dramática de nuestra historia; Orrego (2009) diría, y con razón, que su vida pública fue como una centella: rápida, brillante y trágica. Consignatario del guano, fue fundador del Banco del Perú y miembro de la Compañía Nacional del Guano en 1862; en medio de la guerra con España, fue Secretario de Hacienda en el célebre Gabinete de los Talentos de 1865; durante la epidemia de fiebre amarilla, fue heroico director de la Beneficencia Pública de Lima entre 1867 y 1868 ; eficaz y progresista alcalde de Lima entre 1869 y 1870 ; Presidente Constitucional de la República, el primer civil electo para el cargo, entre 1872 y 1876 ; Presidente del Senado en 1878 , su vida fue trágicamente cortada por la bala de un sargento.

Nieto de un Oidor virreinal e hijo de un célebre poeta y político conservador ${ }^{2}$, Pardo perteneció a la generación que siguió a las guerras de independencia, marcadas por las revoluciones

2 "...en Manuel Pardo confluían las sangres del conquistador, del mercader, del burócrata colonial, del aristócrata, del político y del intelectual; él sintetizó lo mejor de cada uno de ellos. Tuvo el valor y la voluntad de don Gerónimo de Aliaga, quien fuera uno de los trece que cruzaran la línea del Gallo; liberales europeas de 1848. Su educación fue muy esmerada: había estudiado en los grandes colegios peruanos, el liberal Guadalupe y el conservador San Carlos; llevó cursos de filosofía y letras de la Universidad de Barcelona, y en París, cursó economía política en el Colegio de Francia, bajo la dirección de Michel Chevalier, antiguo discípulo de Saint-Simon y colaborador del fastuoso Segundo Imperio, quien lo marcó al punto que en adelante, Manuel Pardo se interesó más por la aplicación práctica de las ciencias económicas que por las humanidades.

Las ideas europeas del segundo tercio del siglo XIX influirían notablemente en el joven peruano: de Chevalier adquiriría la convicción de que debía articularse un Estado fuerte, al que le correspondía intervenir en casos de conflictos de intereses, en oposición a la idea del Estado gendarme en boga en aquel momento; de las ideas sansimonianas, desarrollaría la preocupación por la producción y los aspectos sociales de la modernización, además del contraste entre elementos "productores" y "ociosos" de la sociedad; del positivismo de Auguste Comte, absorbió la fe en el progreso a través de la ciencia y la tecnología; y del utilitarismo de John Stuart Mill, extrajo el pragmatismo y la necesidad de conciliar lo particular con lo general (Mc Evoy, 1994).

"...a pesar de todas las influencias que sobre él obraron, don Manuel Pardo era liberal y su liberalismo era justamente el fulgor de su vida. Es como una gran figura liberal que él resplandece en la historia del Perú. No habría alcanzado jamás la posición sin paralelo que tiene en la historia del Perú si en lugar de ser un espíritu liberal hubiera sido un espíritu conservador. [...] No eran sus cultos el principio de autoridad, el orden, la inamovilidad, la rigidez, la severidad, la intransigencia, la restricción, la opresión, la

la capacidad organizativa y administrativa de su abuelo y homónimo, don Manuel Pardo y Ribadeneyra; la habilidad para los negocios del bisabuelo, don José Antonio de Lavalle; y el amor por la política y la vida intelectual de don Felipe Pardo y Aliaga, su padre" (Mc Evoy, 1994). 
tradición, la religión, el fanatismo, el pasado. Sus cultos eran la libertad, el progreso, la acción, la renovación, la innovación, la república, la democracia, el gobierno civil, el pueblo, la descentralización, la revolución, el idealismo de la guerra de emancipación. El creía en las libertades civiles y políticas, y las reverenciaba. El creía en los derechos del hombre. El sabía que todo progreso humano, en política y en todas las esferas, lo había hecho el liberalismo. [...] Las verdaderas fuentes de su formación mental y espiritual están en la Revolución Inglesa, la Revolución Francesa y la Revolución Americana" (López, 1947, pp. 2-3).

Sin embargo, todo ello se unía a una sincera piedad cristiana, como lo atestiguaría años después, al ser acusado de antirreligioso:

"Prefiero en materia de religión emplear en arreglar mi conducta a sus elevados principios, el tiempo que otros consagran al análisis escudriñador de la del prójimo...

en una palabra y para precisar completamente mi pensamiento, el tipo de mis simpatías no es Torquemada, sino San Vicente de Paul. Creo que para mis opositores benévolos esto basta y que para los malévolos nada sería suficiente" (Espinosa, 2013, p. 145).

Con tal bagaje, Pardo fue un hombre ilustrado, capaz de escribir artículos amplios y enjundiosos sobre diversos temas. Pero además será un nuevo tipo de personaje en la escena política: empresario exitoso y audaz, y a la par, con ambiciones políticas.

El dolor no estuvo alejado de la vida de Manuel Pardo, en especial con el lento sufrimiento de su padre, el literato Felipe Pardo y Aliaga por una progresiva parálisis que lo alejó de la vida pública, el dolor permanente de su madre, y luego las muertes sucesivas de su hijo Manuel (mayo de 1868), de su hermano Felipe (julio de 1868) y de su padre (diciembre de 1868). Todo ello le dio una determinación, no exenta de fatalismo y sangre fría, frente a los desafíos de la vida. Vicuña, citado por López (1947), recordaría uno de sus últimos encuentros con Pardo, donde exhibió dichos rasgos ante una sugerencia para disimular su retorno al Perú en 1878:

Pero él rehusó perentoriamente. "Querido amigo, nos dijo, los que tenemos a cuestas la fatalidad de llevar el nombre de jefes de partido en las Repúblicas de América, no podemos hacer otra cosa sino levantar la bandera y pasar los primeros el puente con ella. No hay alternativa. Es como "be or not to be" de Shakespeare. Por otra parte, yo no le temo a la muerte sino a la manera de morir. Porque desaparecer de la escena de la vida ahogado por una membrana, con el pescuezo roto por un resbalón de caballo, en un tren desrielado y cubierto de aceite y de carbón, es algo que ciertamente no me gustaría. Pero morir en su puesto, cumpliendo dignamente su deber, sirviendo a su país, eso es otra cosa y eso no me espanta". Y luego con su espiritual versatilidad de lenguaje que hacía su conversación tan amena a todos los que le escuchaban, añadió: "¡Y qué diablos! ¿No escribirá Ud. mi biografía si me matan? Pues entonces, démonos prisa, no sea que Ud. se muera antes que yo, como más viejo, y me deje Ud. mirando..." (p. 549).

Pardo inició su actuación pública como inteligente articulista en la Revista de Lima, resaltando la necesidad de promover el progreso material, la necesidad de orden e institucionalidad y la libertad cívica. Su prestigio como financista le abrió las puertas de la Secretaría de Hacienda en noviembre de 1865 , en medio de la crisis generada por el conflicto con España. En tal coyuntura, su labor se caracterizó por un espíritu de honradez, de economía y por buscar el incremento de las rentas públicas, a través de un vasto plan tributario, cuyo fracaso hizo constatar que "el guano no enriquecía a la Nación ni fomentaba la industria, ni el comercio y consiguientemente el bienestar del ciudadano; y segundo, que por su causa, como lo dijo Prado, el Perú habíase convertido en una asociación de holgazanes y logreros" (Dávalos y Lisson, 1926, pp. 226-227). La lucha contra los intereses creados y por largo tiempo existentes, no podía menos de levantar formidable oposición al 
Secretario de Hacienda, quien renunció en noviembre de 1866 .

En diciembre de 1867, Manuel Pardo fue elegido director de la Beneficencia Pública de Lima, cumpliendo una notable labor durante la epidemia de fiebre amarilla, fundando la Caja de Ahorros e iniciando la construcción del Hospital Dos de Mayo. Su popularidad aumentó con su labor como alcalde de Lima entre 1869 y 1870 , misma que fue reconocida por los vecinos con una medalla de oro en enero de 1871 .

En abril de 1871, más de una centena de notables se reunieron en casa de José Antonio García y García a fin de organizar un grupo político, la Sociedad Independencia Electoral, embrión del futuro Partido Civil ${ }^{3}$. Su fundación sirvió, al mismo tiempo, para anunciar la candidatura de Pardo, objeto de especulación ya desde su gestión edil; y en efecto, Pardo preparaba activamente su candidatura presidencial, escribiendo cartas a sus amigos en provincias para sondear cuáles eran sus posibilidades. De allí que la Sociedad Independencia Electoral lograse articular una eficaz red de colaboradores en provincias ${ }^{4}$. Este grupo, presentado oficialmente el 2 de mayo siguiente, buscaba articular a los sectores laboriosos del país a fin de establecer una fuerza superior al de las individualidades aisladas, replanteando el sueño republicano ${ }^{5}$.

"Un candidato civil [...] despertó suspicacias, acrecentadas por sus ideas liberales y la propaganda de sus

\footnotetext{
3 "De la Sociedad de Independencia Electoral nació el Partido Civil. Para su advenimiento coincidieron tres cosas: la presencia de un leader excepcional con las características positivas de un caudillo, la formulación de un programa (cuyas notas más sencillas ante las masas fueron la reacción contra el militarismo y el anuncio de una "República práctica") y la enérgica e inmediata aptitud para ir a los hechos dentro de los cauces de un intenso y combativo proceso electoral". (Basadre, 2005).

${ }^{4}$ Para una lista detallada de los corresponsales de Manuel Pardo en Lima y provincias, en base al Archivo Pardo de la Biblioteca Nacional, Mc Evoy (2007).

${ }^{5}$ Para un estudio más detallado del ideario republicano civilista, Mc Evoy, (2016).

${ }^{6}$ A último momento, Balta dio marcha atrás en el plan golpista, y Gutiérrez siguió adelante proclamándose Jefe
}

opositores. Estos provenían del ejército, algunos sectores de la Iglesia y el pierolismo. Señalaban que un personaje civil, que además era un plutócrata vinculado en algún momento al guano, gobernaría siguiendo intereses de grupo, ya que no tenía, fuera de un partido que él dirigía, ningún cuerpo institucional (como, por ejemplo, el ejército) ante quién responder" (Contreras y Cueto, 2013, pp. 157 y 159 ).

La campaña electoral fue larga y ardorosa, marcada por la oposición de la administración del coronel Balta, quien patrocinó sucesivamente a dos candidatos en oposición a Pardo, para al final, dada la ventaja obtenida por los civilistas, preparar un golpe de estado en colaboración con su ministro de Guerra, Tomás Gutiérrez. Todo terminó en tragedia como es bien sabido 6 , y tras un breve interregno, Pardo asumió la Presidencia el 2 de agosto de 1872 .

El nuevo Presidente debió afrontar un ambiente de crisis general en las instituciones y en la vida económica: la administración pública desorganizada y corrompida, la hacienda pública sin crédito, el ejército anarquizado luego de los hechos de julio de 1872 , la instrucción pública abandonada casi a su suerte, la moral ciudadana quebrantada. Lejos de contar con tranquilidad, la agitación fue constante bajo el régimen de Pardo, pese a sus reiteradas invocaciones al diálogo y al consenso nacional. Alejandro Revoredo, a quien

Supremo el 22 de julio de 1872: cinco días después, el Presidente había sido acribillado en su celda de prisionero, y Tomás Gutiérrez y dos de sus hermanos acabaron linchados por la iracunda multitud y colgados de las torres de la Catedral de Lima. "Para algunos, el populacho de los días 26 y 27 de julio de 1872 es una muchedumbre épica que con castigos ejemplares defiende la inviolabilidad del sufragio, el respeto a la opinión pública y la soberanía popular frente al despotismo cuartelario, felón con su protector Balta, presidente legal del Perú. Es para otros, en cambio, una masa delincuente, azuzada por el dinero y por el alcohol hasta los más horrendos extravíos, para satisfacer pasiones e intereses ajenos" (Basadre, 2005, p. 119). 
cita Basadre, hizo un recuento de nada menos que 37 conjuras y rebeliones en contra del gobierno. Sin embargo, el gran historiador tacneño consideró que tales intentos no tenían comparación con las intentonas que habían afrontado Gamarra o Castilla, pues tenían mayormente un carácter marginal o periférico (Basadre, 2005). Pero el gran rival del líder civilista sería el antiguo Ministro de Hacienda de Balta, el enemigo de los consignatarios, Nicolás de Piérola. La rivalidad entre Pardo y Piérola ocuparía medio siglo de la historia política peruana. En una sugestiva comparación, Santos Chocano, citado por Basadre (2005), decía:

"Pardo es un temperamento flemático; Piérola es un temperamento nervioso. Aquel es la robustez; éste, la agilidad. El jefe del partido civil es un hombre práctico; el jefe del partido demócrata, es un gran imaginativo. Así es como Pardo logra inspirar respeto, y Piérola cariño. El uno tiene partidarios; el otro fanáticos. Con el uno prosperan no pocos, por el otro se hacen matar muchos. Pardo es el tipo imponente del Jefe de Estado; Piérola es el tipo irradiante del caudillo romántico" ( $p$. 140).

Y a pesar de tal agitación, Pardo se esforzó en materializar sus proyectos en el gobierno; el radical González (1938), crítico con el civilismo, escribiría con cierto respeto en 1902:

"A pesar de la incesante inquietud en que gobierna (siempre amenazado por la ambición morbosa de Piérola) Manuel Pardo inicia reformas trascendentales y concibe grandes proyectos. Funda escuelas y contrata profesores europeos, deseando infundir nuevo espíritu a la educación nacional; crea los Concejos Departamentales, queriendo avanzar un paso en la descentralización política y administrativa; establece los registros civiles, preparando el terreno para la secularización de la vida social, etc. Mucho bueno habría realizado, merced a su carácter enérgico y emprendedor, si hubiera tenido auxiliares más aptos y enemigos menos pérfidos [...] Con todos sus defectos, mejor dicho, con todos sus errores (algunos gravísimos) Pardo se diseña como el único mandatario que, después de Santa Cruz, haya concebido un plan político y abierto uno que otro surco luminoso (...)" (pp. 135-136).

\section{EL PENSAMIENTO JURÍDICO DE PARDO}

Evidentemente Manuel Pardo no dejó una obra sólida en el sentido de los teóricos del derecho. Hombre práctico al fin, sus ideas las plasmó en sus artículos y discursos, textos en los que proponía soluciones a los problemas del Perú decimonónico. $Y$ en tal sentido, se puede encontrar numerosas menciones al derecho y al rol del Estado. Pardo buscó rescatar los ideales sobre los que juzgaba se fundó la República, en especial el progreso material, la necesidad de orden e institucionalidad y la libertad. Todos estos ideales los fundió en un ideario político capaz de calar en la ciudadanía, "...nada menos que la fundación de la República Práctica, de la República de la Verdad, convirtiendo en realidad las promesas de medio siglo, las palabras en hechos, las teorías en instituciones verdaderas, la aplicación intercadente y caprichosa de la ley en la posesión tranquila del derecho" (Pardo, s.f., p. 417).

Pardo no quería entonces, una aplicación casual de la ley como había sucedido hasta entonces en muchos casos, basta con recordar las ácidas burlas del Murciélago Manuel Atanasio Fuentes (Ramos, 2002), sino que buscaba la organización de la vida peruana a través del derecho. O como diría uno de sus discípulos, Candamo citado por Basadre (2005), en 1901:

"El día que arraiguemos en nuestro pueblo hábitos de orden, de estricto cumplimiento de la ley y, más que todo, de moralidad política, entonces y solo entonces podremos conocer y apreciar los beneficios de la ley; pero mientras no suceda esto estaremos haciendo siempre la labor de Penélope, deshaciendo hoy lo hecho ayer y deshaciendo mañana lo que hacemos hoy y confirmando cada vez más la opinión que tenía de nosotros un célebre sabio italiano que 
decía: el Perú no es un Estado constituido, sino un territorio habitado" (p. 28).

\subsection{El apego a la Constitución}

El medio siglo que transcurrió entre 1821 , en que surgió el Estado Peruano con el Protectorado de San Martín, hasta la conformación del Partido Civil en 1871 , fue un periodo de continua inestabilidad, fenómeno común en América Latina.

Los instintos y las pasiones han dirigido solos a los pueblos en la tenebrosa atmósfera, en que se ha desarrollado la primera época de nuestra vida política: en ella se han dado un combate a muerte todos los sentimientos y los intereses que animaban y sostenían esas sociedades en metamorfosis (Pardo, s.f.).

La nueva generación que seguía a la de los hombres de la Independencia tenía frente a sí el desafío de crear una nueva institucionalidad, y tal idea partía por la defensa de la Constitución como norma básica dentro de una sociedad, pero al mismo tiempo, en un país como el Perú, que había visto correr raudales de dinero por sus arcas, se debía reconocer que la panacea constitucional no era suficiente. El Congreso que elaboró la Constitución de 1860 , es ilustrativo en el sentido de reformar el criticado texto constitucional de 1856, y a la par, legislar para incentivar la construcción de obras públicas, especialmente ferrocarriles. Pardo comentó al respecto, que "EI Perú estaba cansado de la arbitrariedad; su más vivo deseo era verse ya constituido, marchando por una senda legal", pero a la par,

"El Congreso de 1860 es fiel intérprete de la actual opinión del Perú. En ella, la sed de mejoras materiales lo domina todo [...] Hubo un tiempo en que el Perú creyó en la necesidad de una Constitución [...] pero tras la esperanza vino la fría lección de la práctica inexorable y no tardó la época en que los pueblos se dijeron al oído sin que nadie se atreviera a repetirlo en alta voz: ¿para qué queremos una Constitución? ¿Para qué sirve una Constitución? ¿Las Constituciones malas empeoran nuestra suerte? ¿Las Constituciones buenas alivian nuestros males? Las Constituciones son por ahora una letra muerta... Triste verdad, verdad desoladora, pero la verdad real sentida por el Perú desde Ecuador hasta Bolivia. ¿Es laudable semejante escepticismo? No lo creemos, pero entre tanto es el resultado necesario de cuarenta años de luchas por palabras y de sangre vertida por ambiciones personales" (Pardo, s.f., p. 158).

De esta forma, Pardo expresaba lo que sigue siendo una realidad constante en nuestra cultura cívica, y más en la época de los caudillos militares: la poca valoración que se tenía por la Constitución.

\subsubsection{Las relaciones entre el Ejecutivo y el Legislativo}

Pardo creía en la necesidad de un Gobierno fuerte, pero no dictatorial. El diseño de la Presidencia de la República establecido en la Constitución de 1860 había reforzado notablemente el poder presidencial, a diferencia del texto liberal de 1856. El primer Presidente civil estaba dispuesto a utilizar todas las atribuciones constitucionales en aras de su idea de una República práctica, pero para ello juzgaba indispensable la colaboración con el Congreso, apegando su conducta a la institucionalidad, ya que su gobierno dependía de las leyes dictadas por el Congreso:

“...mi propósito constante será conformar mi política con la opinión de la mayoría de las Cámaras, que es igualmente la opinión del país; y en mi deseo de fundar con lealtad el sistema parlamentario, os aseguro, señores, que deploro el que una disposición constitucional no me permita llevar al Gobierno a los miembros del Congreso, sin que pierdan su derecho de representar el país. Sin esa circunstancia, los Representantes de la nación llevarían periódicamente al Poder Ejecutivo el espíritu de las Cámaras, que es el espíritu del país, y debe, por lo tanto, ser el que anime constantemente la administración" (Pardo, s.f., pp. 417-418). 
Y en efecto, la administración de Pardo respetó la opinión parlamentaria, sin apelar a medios como la clausura del Congreso o la supresión de los elementos opositores. Los ministros fueron responsables de sus actos ante el Congreso, destacando los debates entre el diputado Luciano Benjamín Cisneros y el ministro de Gobierno Francisco Rosas.

Años después, en 1878, ya siendo Presidente del Senado, Pardo reflexionó sobre el rol de una Cámara Alta: sus funciones requerían de una "atmósfera serena", puesto que la misión de este cuerpo legislativo era "apagar las pasiones ardientes, elevando la mente a la alta y fría esfera de las ideas"; en otras palabras, representar la voz de la razón frente a la acción e impulso emanados de la Cámara de Diputados.

“...en medio de las disidencias políticas, que alejan a los hombres, hay siempre un lazo que los une: el del amor a su país y el vivo anhelo por su felicidad. Ocupémonos todos pues de ganar los favores de la nación en este terreno, que por dicha nuestra es bastante ancho para que todos quepan. Unámonos todos para servir las ideas que satisfagan sus necesidades y para combatir las pasiones que la conmueven: y así no sólo habremos hecho buenas leyes sino que habremos devuelto la calma a los espíritus y la paz a la sociedad" (Pardo, s.f., p. 482).

\subsubsection{La irrestricta libertad de prensa}

Convencido de la necesidad de la plena libertad de expresión dentro de un sistema democrático, Pardo llevó su tolerancia al extremo de permitir la circulación sin control alguno, de pasquines que llegaban a incitar a su propio asesinato ${ }^{7}$.

"Difícilmente se hallará en la historia nacional un hombre tan infamado, tan escarnecido, tan vilipendiado como el Jefe del Civilismo. La guerra que se le movió

\footnotetext{
7 Por ejemplo, el periódico satírico La Mascarada, el 15 de agosto de 1874, publicó una caricatura recordando la muerte de Julio César; César era, en este caso, Pardo, quien ingresaba al Senado seguido de personajes vestidos a la usanza romana, mientras ocultos detrás de la estatua del general Prado, se hallaban los conjurados. La leyenda decía:
}

para cerrarle el camino a la Presidencia se recrudeció para derribarle del poder. No hubo injuria que no se le infiriera ni abominación que no se le imputara. Una cuadrilla de mercenarios y aventureros se infiltró en las redacciones de los periódicos para derramar los insultos y forjar las calumnias. Los Neto, los Rojas y Cañas, los Jaimes, los Palma, en fin, todos los condottieri de la pluma trabajaban en una faena vergonzosa pero lucrativa: con una mano apuñalaban la honra de Pardo, con la otra recibían el oro de Dreyfus" (González, 1938, p. 137).

Con su accionar, Pardo instaló la idea de que más daño provocaba los excesos en reprimir la libertad de prensa, respondiendo al insulto con el razonamiento, dejando a la opinión pública con un rol regulador. Por ello, creyó conveniente despertar la responsabilidad del periodista, mediante la idea de un Tribunal de Honor de la Prensa, en aras del respeto de la moral profesional.

\subsection{La reforma de la burocracia}

La empleomanía era una muestra de que no se había logrado construir en medio siglo, un Estado moderno. La fragilidad de las instituciones dejaba el manejo del erario en manos de una burocracia ineficiente, cuando no corrupta, basada en buena cuenta en las relaciones de clientelismo sobre la renta del guano. Vale la pena recordar los datos de Shane Hunt en el sentido que el $29 \%$ del total del dinero que ingresó a las arcas nacionales por la venta del guano, se destinó al aumento de la burocracia civil, y otro $24,5 \%$ fue consumido por la burocracia militar (Hunt, 2011).

Desde su gestión como Secretario de Hacienda, Pardo había apreciado ese problema. Una idea que aún hoy es tema de actualidad como lo es la Ley de Servicio Civil, ya estaba presente en el ideario

"El último día de César. La historia es un espejo donde la humanidad halla consejo". Una semana después, el Presidente salvó de un atentado en la Plaza Mayor de Lima; cuatro años después, la bala de Montoya mató a Pardo a la entrada del Senado. 
pardista a través del intento de establecer un escalafón dentro de la administración pública a fin de organizar los ascensos y la movilidad en la burocracia estatal, dejando de lado el compadrazgo y el clientelismo típicos de los caudillos anteriores.

Sin embargo, aplicar tales ideas en el gobierno civilista fue difícil. La crisis económica desatada luego de los grandes empréstitos contratados en los años de Balta, golpeó duramente al primer gobierno civil, y más frente a una población acostumbrada a décadas de prácticas clientelistas sobre la débil base de la renta guanera.

"No habiendo industrias ni capitales, las gentes de buen abolengo acudían a las dependencias del Estado, y como éstas eran escasas, lo menos la mitad de los pretendientes, viviendo fuera del Presupuesto, se morían de hambre. Reducido en 1872 el ejército a 2,500 hombres, un setenta por ciento de los militares inscritos en el escalafón quedaron sin servicio y hambrientos, arrimados a lo que entonces se llamaba la indefinida. Si Pardo hubiera recibido y repartido los millones en la forma en que los anteriores gobiernos lo habían hecho, no hubiera tenido ni la cuarta parte de las revoluciones que pusieron en peligro la estabilidad de su gobierno. Por esos lejanos días del pasado siglo, era un crimen anunciar al pueblo que el Estado estaba en bancarrota y un motivo de censura no hipotecar o vender el país para seguir viviendo en bonanza. "Son los enriquecidos en el cuatrienio 1868 a 1872 , decía Pardo cuando estaba en la Presidencia, los que más insultan nuestra miseria de hoy, y los que más mofa hacen de la estrechez en que vivimos" (Dávalos y Lisson, 1926, p. 314).

Pardo debió lidiar con el clientelismo político prácticamente desde su asunción al mando. Numerosas cartas hablan de la esperanza por parte de varios de sus partidarios en provincias por obtener un cargo público una vez asumida la Presidencia (Mücke, 2010). Sin embargo, en la medida de sus posibilidades, el gobierno civilista se esforzó por forjar la idea de la República Práctica. La búsqueda de cuerpos administrativos y técnicos capaces de continuar el proyecto modernizador del Perú explica la fundación de la Facultad de Ciencias Políticas y Administrativas, y la de la Escuela de Ingenieros a cargo de profesionales extranjeros capaces de traer al Perú los últimos avances europeos en tales materias, profesionales como el jurista francés Paul Pradier Foderé y el ingeniero polaco Eduardo de Habich respectivamente, poniendo de manifiesto la importancia que para el régimen civilista tenía el mérito personal y el estudio frente a la improvisación de los regímenes previos (Mc Evoy, 2007).

\subsection{La idea democrática}

La ideología esbozada por Pardo buscó, sin perderse en complicadas elaboraciones intelectuales, movilizar las energías del pueblo en aras del desarrollo material por medio de un eslogan de fácil comprensión, que articulase los ideales republicanos aurorales: la democracia como sistema y el progreso económico como tarea urgente (Mc Evoy, 2007).

"Señores, el sistema republicano es el que concede a los ciudadanos mayores derechos, pero él les impone también, sus más graves obligaciones. La República exige de sus hijos el cumplimiento constante, austero y valeroso de los deberes públicos: abandonarlos, o desdeñarlos o avergonzarse de cumplirlos, es minar por su base la organización entera" (Pardo, s.f., p. 382).

Pardo pronunció estas palabras al fundarse la Sociedad Independencia Electoral, embrión del futuro Partido Civil, en abril de 1871 , palabras que no pierden aun actualidad en el Perú, pues nos hacen preguntarnos si estamos formando a nuestra juventud en el concepto del cumplimiento de los deberes cívicos. Y los mítines de Pardo se caracterizaron por ese tipo de mensaje:

"La sociedad peruana ha demostrado esta vez, que tiene la conciencia de sus deberes, la voluntad de hacer respetar sus derechos y la inteligencia, la iniciativa necesaria para 
organizarse de la manera más conducente al triunfo de sus opiniones. Tal es el programa de los pueblos republicanos; y porque hoy aparecen en nuestro estado social aquellos síntomas, es por lo que todos esperamos con razón una nueva época, en que los pueblos pesen con su propia opinión y con su propia iniciativa en la balanza de sus destinos" (Pardo, s.f., p. 390).

Es decir, el primer deber de los ciudadanos es el hacer respetar sus derechos, pero al mencionar la inteligencia y la iniciativa, Pardo recalca una idea clave hasta nuestros días: la crisis de los partidos se basa en una deficiencia del ciudadano al no interesarse en la res publica, no saber formar cuerpos civiles capaces de brindar a la sociedad el camino de la política. Por ello, urgía a la formación de partidos más que de facciones efímeras y electoreras, cuando no oficialistas.

“¿Cómo no cambiarían de marcha los partidos ante esta nueva situación, en que el gobierno protege a todos con la igualdad de la justicia, y en que el pueblo mismo, sacudida la indiferencia y educado para la asociación, viene a sostenerlos y aun a representarlos? ¿Cómo no variaría la táctica de los partidos cuando libres y organizados puedan contar sus fuerzas, aun sin necesidad de la consagración legal de su poder respectivo? Celebremos, pues, por nuestro país, más todavía que por nosotros mismos, este adelanto no sentido, pero indisputablemente realizado en nuestras costumbres políticas [...] y cuando veamos a los demás partidos organizarse, como nosotros, franca y públicamente, no los miremos airados, sino al contrario, regocijémonos en nuestro patriotismo, porque ellos vendrán a dar un nuevo testimonio del progreso nacional" (Pardo, s.f., p. 384-385).

Una de las críticas comunes al civilismo fue el hecho de ser los representantes de la oligarquía, critica válida hasta cierto punto si hablásemos de los inicios del siglo XX, esto es, el segundo civilismo. Los estudios recientes nos indican otra perspectiva al hablar del primer civilismo, puesto que estuvo integrado por numerosos grupos sociales: profesionales, comerciantes, artesanos y obreros. La membresía inicial de la Sociedad Independencia Electoral incluía carpinteros, tapiceros, sastres, joyeros, tipógrafos y albañiles. La manifestación popular convocada por esa asociación contra la interferencia de Balta en la campaña electoral, representa el primer movimiento social partidario de la política moderna bajo signos republicanos y liberales. Se concentraron 14 mil personas en marcha hacia la Plaza de Acho, donde se celebró el primer mitin propiamente moderno de la historia peruana, el 6 de agosto de 1871, donde Pardo lanzó su candidatura a la Presidencia de la República.

Electo Presidente, la idea democrática no dejó de estar en el pensamiento de Pardo, y a lo largo de distintos medios, buscó consolidar dicho ideal.

"El Perú ha querido realizar la República, y la viene realizando hace tiempo entre la incredulidad y las pasiones, sosteniendo primero dentro del terreno de la ley, una lucha obstinada contra todos los elementos de la autoridad, coaligados para oponerse al derecho de los pueblos, defendiendo enseguida con su voluntad poderosa el edificio constitucional que él había levantado de entre ruinas y desvaneciendo con su sola actitud las tentativas para volver a derribarlo, ofreciendo así el espectáculo glorioso de un pueblo atalaya, vigilante y defensor denodado del orden constitucional, tolerando al mismo tiempo, con la tranquilidad del fuerte, los excesos de la libertad y deplorándolos únicamente por el crédito de la República" (Pardo, s.f., p. 435).

\subsubsection{La descentralización, escuela de democracia} La descentralización en el Perú tuvo una historia tortuosa. Los antecedentes de 1828 y 1834 fracasaron, y con la era del guano, se agravó el centralismo, ya que sus rentas se concentraron en Lima, y se derogaron las contribuciones que recaudaban las provincias.

La visión descentralizadora fue notoria en Pardo a lo largo de su gestión hacendaria en 1865-1866, 
siendo evidentes en los Decretos del 28 de julio y del 3 de septiembre de 1866, que clasificaban las rentas $y$ gastos públicos en generales $y$ departamentales. Según el Secretario de Hacienda, tal esquema adjudicaría a los municipios la contribución de aguardientes, y a los departamentos los servicios especiales de cada contribución, para propiciar "un ensayo de descentralización de ciertos servicios en la parte económica, a condición que no se descentralice, al menos por ahora, la administración de ciertas rentas que empiezan a recaudarse bajo un sistema nuevo que exige tiempo para arraigarse y darse a conocer" (Pardo, s.f., p. 223). Ya como alcalde de Lima, Pardo pudo apreciar los problemas que aquejaban a las Municipalidades peruanas, en especial la carencia de rentas, por lo que buscó generar rentas alternativas, además de la contratación del primer empréstito de la historia municipal limeña (Mc Evoy, 1994). Electo Presidente, Pardo (s.f.) expresaba que:

"La reorganización municipal servirá de escuela política a los ciudadanos, utilizará en provecho de cada localidad los elementos hoy latentes e inactivos que todas ellas encierran, emancipará a los pueblos de la tutela administrativa en que hoy viven, y libertará a la vez al Gobierno de conocer en ese crecido cúmulo de asuntos, que siendo ajenos de la administración general, le imponen, sin embargo, obligaciones, cuyo cumplimiento le es casi imposible, subsistiendo íntegra, por otro lado, su responsabilidad ante los pueblos" (p. 415).

Con la Ley Orgánica de Municipalidades, promulgada el 9 de abril de 1873, el régimen civilista delimitó las atribuciones de la administración local de la República, a la cual dividió en departamental, provincial y de distrito (artículo $1^{\circ}$ ). Existiría un Concejo Departamental en cada capital de los departamentos entonces existentes, además de los respectivos Concejos provinciales (este último existiría aún en la capital de departamento) y distritales (artículo $5^{\circ}$ ). La Ley de 1873 abría las puertas de la institución municipal a los extranjeros, pues exigía como requisitos el saber leer y escribir, tener al menos dos años de residencia en la jurisdicción del Concejo, ser mayor de edad, y ejercer una industria o pagar una contribución al Estado (artículo 10); a la par, en aras de una independencia municipal del aparato estatal, prohibía integrar los Concejos municipales a militares y empleados públicos o judiciales en servicio (artículo $11^{\circ}$ ). Los Concejos tenían el derecho de dictar reglamentos "cuidando de que no se opongan a las leyes vigentes" (artículo $25^{\circ}$ ), además de votar arbitrios y levantar empréstitos sin necesidad de la aprobación del Congreso pero sí de los Concejos Departamentales (artículo $103^{\circ}$ ).

Con ello, buscó transferir a los municipios la recaudación de las contribuciones, a fin de aplicarlas para el beneficio de sus comunidades, cortando su dependencia del gobierno central para hacer de las Municipalidades entes autónomos, encargados de la administración local en todos sus ramos, excepto el judicial. El objetivo de esta progresiva independencia, consideró Mc Evoy (2007), era fortalecerlas como "escuelas políticas" (p. 271), como un tímido ensayo de las ideas federalistas del republicanismo inicial. No obstante, el proyecto pardista, lejos de impulsar el federalismo (como lo haría, al menos en su declaración de principios, el Partido Demócrata de Piérola), se esforzaba por alentar la iniciativa municipal, ya que "en el municipio es donde reside la fuerza de los pueblos libres. Las instituciones municipales son a la libertad lo que las escuelas primarias para la ciencia: ellas son las que la ponen al alcance del pueblo, le hacen gozar de su uso pacífico y le acostumbran a servirse de ella. Sin instituciones municipales, una nación puede dotarse de un gobierno libre, pero no tiene el espíritu de la libertad" (Tocqueville, 2007, p. 95). Pardo consideraba a la Ley Orgánica de Municipalidades, junto con la Ley de Guardias Nacionales, como "las bases de la República; de esa República de la verdad, que se levantará más grande mientras más combatida", y tenía fe "en que a pesar de las muchas dificultades con que tropezará [...], y por más que en su práctica se 
desvíen o tropiecen algunos pueblos, los que por su ilustración se han colocado a la cabeza de sus hermanos, les enseñarán el modo de ejercer los amplísimos derechos que concede esa ley" (Pardo, s.f., p. 436). Este intento descentralizador duró menos de siete años, ya que en medio de la guerra con Chile, la dictadura de Piérola cesó las instituciones municipales mediante Decreto del 14 de enero de 1880 aduciendo sus "gravísimos defectos", y volviendo a crear nuevas Municipalidades, únicamente provinciales $y$ distritales.

\subsection{La educación para preparar al ciudadano}

La preocupación de Manuel Pardo por la educación venía de larga data. En su Memoria como Director de la Beneficencia, dedicó una sección al tema de las escuelas gratuitas para niños y niñas sostenidas por su institución con un pequeño gasto, opinando que "una buena educación popular lleva a la prosperidad de una nación y no puede menos de desearse ver ensanchado ese caudal inmenso de bien, obtenido con tan pequeños sacrificios" (Pardo, s.f., p. 352). Siendo Alcalde de Lima, dicha idea no dejó de preocuparlo, denunciando la negligencia y abuso en la educación pública; al final de su gestión municipal, Pardo, citado por Mc Evoy (2004), declaraba haber cuadriplicado el número de alumnos bajo la administración educativa municipal, además de estimular el cumplimiento de los deberes cívicos en los sectores populares. Electo Presidente, Pardo mantuvo su apuesta por el fortalecimiento de la educación, incluso a pesar de la grave crisis económica:

"Hay, sin embargo, algunos servicios públicos, como el de la instrucción popular, en los que el país debe hacer todo el gasto necesario para conseguir el resultado, porque la educación de cada ciudadano es la primera condición de la verdadera grandeza de las naciones" (Pardo, s.f., p. 417).

La educación, junto con la participación de la población organizada en las tareas del gobierno, era para el líder civilista, el único camino posible para una transformación estructural del país. La continuidad en las políticas era, pues, elemento esencial para que estos cambios pudieran cristalizarse. Para el mandatario no eran las leyes las que debían reformarse sino los hombres "y esta reforma no se obtiene sino por la educación y por la práctica misma de la población en los asuntos de su localidad" (Mc Evoy, 2016, p. 125).

Pardo buscaba establecer un sistema estatal de educación primaria libre y universal. A través de la educación primaria, Pardo sentía que cada peruano podría desarrollar y proteger su propia dignidad, a la par que contribuir más efectivamente en el desarrollo material y cultural del país. Mientras la población fuese iletrada, el Perú no podría emerger de su atraso.

Tres medidas se complementaron en aras de la construcción de la República Práctica civilista. En primer lugar, la Ley Orgánica de Municipalidades de 1873, que asignaba a los Concejos respectivos responsabilidades en el desarrollo educacional. En segundo lugar, el Reglamento General de Instrucción Pública del 18 de marzo de 1876, que establecía los niveles de instrucción en primaria (bajo responsabilidad de los Concejos Provinciales y Distritales), media (a cargo de los Concejos Departamentales) y superior, bajo la dirección del Ministerio de Justicia, Instrucción, Culto y Beneficencia (asesorado por un Consejo Superior de Instrucción Pública con amplias facultades); y que establecía la obligatoriedad de la instrucción primaria y su gratuidad en el primer grado. Por último, el establecimiento de la contribución de escuelas: un sol al semestre en la sierra y dos soles en la costa a todos los ciudadanos entre 21 y 60 años. Y la población indígena no estaba fuera de la visión pardista:

"La misión civilizadora de Pardo pedía específicamente la asimilación indígena a través de un sistema estatal de escuelas primarias. Aunque jamás consiguió el respaldo para su proyecto educativo, Pardo sí le dio inicio. Él abrió una de las primeras escuelas de oficios para indios en la ciudad de Ayacucho. Allí, un selecto grupo de muchachos fue preparado para ser 
carpinteros, albañiles y herreros. Diseñado a medida por el Estado, el 'nuevo indio' debía ser convertido en la clase obrera peruana. Con esa finalidad el Estado debía penetrar en las comunidades quechuas $y$ aimaras, erradicando las lenguas $y$ costumbres indígenas a nombre de la unidad nacional. En forma bastante similar a los Borbones del tardío siglo XVIII que pedían la 'extirpación de la lengua indígena', Pardo promovió la hispanización forzada de los pueblos nativos. Pero así como los reformadores 'hispanistas' se habían topado con la firme resistencia 100 años antes, el mismo Pardo tuvo que vérselas con la resistencia de las élites serranas interesadas en las formas de discriminación coloniales. De hecho, hasta bien entrado el siglo $\mathrm{XX}$, muchos terratenientes provincianos de Perú $y$ Bolivia vieron la alfabetización y la educación indígena como una amenaza al orden social. Para los hacendados era un lugar común prohibir que sus peones fueran alfabetizados. Estas duras realidades de la sierra peruana desinflaron los grandiosos planes que Pardo tenía para la regulación de las lenguas. Su misión civilizadora fue reducida a algo meramente simbólico: ¡ordenó que el Estado imprimiera mil copias de un diccionario castellano-quechua para que fueran distribuidos entre los indios! [Gramática y Diccionario español-quechua y quechuaespañol del profesor José Dionisio Anchorena] A decir verdad, esta no habría de ser una 'revolución integradora', pero las políticas culturales de Pardo sentaron las bases discursivas para los proyectos 'civilizadores' de comienzos del siglo XX" (Larson, 2002, pp. 111-112).

\footnotetext{
${ }^{8}$ Pese a que el proyecto pardista consideraba la enseñanza religiosa en los cursos de primaria, muchos clérigos veían al diseño educativo más práctico que espiritual. Criticaron duramente la difusión, por parte del gobierno, del periódico El Educador Popular, y hubo un sacerdote en Arequipa que
}

Sin embargo, la esperanza en que los peruanos pagasen por la educación de sus hijos o que los Municipios atendieran mejor a la educación pública quedó desvanecida: la oposición clerical ${ }^{8}$ y la crisis económica frustraron tales ideas; los gobiernos que siguieron a Pardo, agobiados por la crisis económica y la guerra, no hicieron mucho: basta recordar la afirmación de Piérola en el Mensaje Presidencial de 1897, "nada eficaz he podido intentar acerca de ella". Sería precisamente el hijo del fundador del civilismo, José Pardo, quien en 1905 recuperase para el Gobierno central la dirección de la educación primaria, impulsando la mayor inversión en educación hasta entonces vista en nuestra historia.

\subsection{El derecho penal en aras del progreso}

En 1861, el Perú aún no tenía un Código Penal. En aquel momento, el Congreso dispuso la creación de una Comisión (la tercera) encargada de preparar la legislación penal y procesal penal. Pardo, siempre inquieto ante los problemas del momento, publicó un artículo titulado "Algo sobre el proyecto de Código Penal. Vagancia". Pardo felicitaba como una muestra del progreso nacional la redacción de dicho proyecto, de urgente necesidad, por estar "llamado a ejercer una influencia poderosa y directa en nuestra sociedad, cuya tendencia a la licencia en todos los ramos de la moral del hombre es cada día más manifiesta" (Pardo, s.f., p. 190)9 Se declaraba agradablemente sorprendido al ver la firmeza y esmero con que se buscaba reprimir la sedición y la rebelión, "que han adquirido ya fuero de costumbres nacionales", pero a la par, se lamentaba de la omisión de "otro vicio de nuestra población, rémora del progreso para el Perú”, la vagancia. Influido por las ideas penales francesas, Pardo (s.f.) definía vago como "aquel que no tiene domicilio cierto ni medios de subsistencia y que pudiendo no ejerce habitualmente oficio o profesión alguna" (p. 191). Admitiendo que no era

incitó a quemar sus ejemplares. Además cuestionaban los planes del gobierno para la asimilación de los indígenas en aras de proteger la pureza espiritual de los indígenas frente a la civilización urbana (Pike, 1969).

${ }^{9}$ Pardo (1861) 
la persona idónea para entrar a discutir el punto desde una óptica jurídica, Pardo analizaba la figura de la vagancia desde la óptica social y práctica, considerando que "el político y el legislador no pueden mirar en el vago sino al ciudadano que vive degradado, al individuo útil que se mantiene la holganza del sudor de sus hermanos, al obrero que debía contribuir a la riqueza y prosperidad de la nación y que por el contrario contribuye a su miseria" (Pardo, s.f., p. 193). Superaría en mucho el tiempo que se me ha concedido si entrase a examinar en detalle el tema de la vagancia; bástenos decir que en descargo de Pardo, existían en su momento, antecedentes en la legislación ateniense y romana, además del derecho inglés, castellano y francés, en el sentido de reprimir la vagancia; que una de las banderas de la campaña electoral de 1871 fue el rescate del papel fundamental del trabajo como generador de orden, progreso, decencia y dignidad; y que en 1922, se aprobó la Ley $\mathrm{N}^{\circ} 4891$, Ley de Vagancia, que estuvo vigente hasta 1986.

En la ceremonia de toma de mando de 1872 , Pardo no dejó de llamar la atención a los congresistas sobre "la insuficiencia de nuestra legislación penal y el peligro que envuelve para la moral pública, como para la garantía de los derechos de los ciudadanos, la lentitud que se nota frecuentemente en los procedimientos de la justicia criminal. Reformarla vigorosamente de manera que garantice con la necesaria eficacia, los derechos de los ciudadanos y el ejercicio de la autoridad, es el gran problema de la sociedad política que estáis en el deber de resolver porque no está resuelto en el Perú" (Pardo, s.f., p. 416).

\subsection{El Estado y la economía}

El rol del Estado en el proceso productivo fue un tema constante en el pensamiento de Pardo, siendo evidente la importancia que tenía para él, el definir con claridad dicho rol. Esta idea la evidenció desde sus artículos en la Revista de Lima, donde llamaba la atención al gobierno para que se adoptasen medidas antes que la producción guanera desaparezca.
"Crear retornos que suplan el huano [sic], crear rentas fiscales que reemplacen las del huano [sic]: he aquí el problema. Fomentar la producción nacional; he aquí la resolución: ella nos dará retornos para el comercio; ella nos dará rentas para el Estado. En la producción nacional, en la riqueza pública será donde encontremos las entradas para nuestro tesoro, cuando la actual renta desaparezca. El aumento de valores en todas las ramas de la actividad nacional permitirá el aumento de las contribuciones sobre la tierra que sólo se pueden pagar cuando la tierra produce; sobre la industria que sólo se obtiene cuando la industria florece; sobre la propiedad urbana, consecuencia del aumento de la población; y por último y más que todo de las contribuciones indirectas, como la de aduanas que crece sólo donde hay movimiento industrial y comercial (Pardo, s.f., pp. 116-117).

Lejos de ser un proyecto para un desarrollo exportador orientado hacia los mercados exteriores, pareciera que el proyecto de Pardo era más un llamado al desarrollo del potencial productivo peruano, lo que en el siglo XX, habría sido llamado industrialización por sustitución de importaciones. La construcción de una red ferroviaria interna habría reducido los costos de transporte, permitiendo un surgimiento de manufacturas internas para el mercado local (Klaren, 2004).

"Y qué medio más fácil, más rápido y más poderoso de aumentar con la producción nacional a un mismo tiempo la riqueza de los particulares y del Estado ¡Qué medio más expedito y más sencillo que las vías de comunicación? [...] Ya hemos dicho: si en las naciones europeas el papel de un camino de hierro se reduce a facilitar $y$ activar las comunicaciones entre dos puntos del territorio, en el Perú su misión es de crear esas relaciones que no existen entre lugares que están incomunicados unos de otros; en Europa ellos facilitan el tráfico y el comercio, fomentan así la industria y dan mayor valor a la propiedad; en el Perú lo crearán todo: comercio, 
industria y hasta la propiedad, porque darán valor a lo que hoy no tiene" (Pardo, s.f., pp. 117-118).

Aunque Pardo fuera un liberal, no era un enemigo acérrimo de la intervención del Estado en la economía. Creía que el Estado no debía aplastar la iniciativa privada, ni comprometer su soberanía. Cuando el mercado no funcionase adecuadamente, el Estado debía actuar. No es casual que se expresase con cierta admiración del rol proteccionista jugado por la Corona española en el siglo XVIII, y compararlo con la incuria de los primeros años republicanos.

"...a pesar del estanco y de los reglamentos, se seguía entonces un sistema, con sus defectos, pero también con sus ventajas: se regulaba la producción pero se le favorecía al mismo tiempo; la autoridad local protegía al labrador y al industrioso e impedía las depredaciones; fomentaba todo nuevo cultivo y toda nueva industria; hacía caminos y construía puentes, mientras que bajo el sistema económico que hoy está plantificado, llamado por algunos de libertad, y que nosotros, que respetamos demasiado esta palabra, no llamaremos sino de abandono, no se regula, es cierto, la producción ni se dirige la industria, pero tampoco se la protege ni se la fomenta; y el labrador y el artesano están a merced del salteador y del ratero; ni se favorecen las nuevas industrias o los nuevos cultivos, ni se piensa en construir puentes, ni caminos" (Pardo, s.f., p. 138).

Como Secretario de Hacienda, Pardo puso énfasis en la necesidad de revivir un sistema tributario luego de las aboliciones de contribuciones en medio del apogeo guanero. Para ello propuso contribuciones sobre la tierra, el capital y el trabajo, pero sus medidas fueron derogadas tan pronto cayó el régimen de Prado, sin hacer un adecuado análisis de la conveniencia de las reformas hechas.

Una de las mayores paradojas de la historia peruana fue que Pardo, el gran defensor de un uso racional y previsor de la renta guanera, llegó a la Presidencia cuando la ficticia bonanza construida sobre dicho recurso, empezaba a desmoronarse. Pardo reveló la gravedad de la situación financiera del Perú en su Mensaje al Congreso en septiembre de 1872, explicando que todos los ingresos del guano debían ser aplicados a la deuda externa, que el déficit ascendía a más de 8 millones de soles, y que sólo podía salvarse en parte, aumentando los derechos de aduana y creando un impuesto a la importación del salitre (Pardo, s.f.). "No habiendo habido en el Perú en los años que terminaron en 1876 más riqueza que la del guano, y habiendo sido esta riqueza precaria, todo en el orden social y económico comenzó a desmoronarse en cuanto principiaron a faltar los recursos que el maravilloso fertilizante producía. Fuera del guano no había nada. El salitre era una promesa y nada más que una promesa, con el aditamento de que en esos años no solamente no sustituía la renta que comenzaba a faltar, sino que siendo un competidor del guano, era mucho el daño que comenzaba a hacerle. Existían la minería y la agricultura, pero la falta de capitales, de caminos, de conocimientos científicos y de garantías pusieron a la primera en deplorable estado de postración" (Dávalos y Lisson, 1926, p. 372).

Sin embargo, el gobierno de Pardo se esforzó en promover el desarrollo de las industrias nacionales, como las fábricas textiles de Garmendia en el Cuzco. Pero el gran problema era la constante baja del guano y la competencia del salitre. Entonces, ¿cómo aprovechar la nueva riqueza salitrera? Los liberales doctrinarios defendían la idea de dejar la explotación y comercio del nitrato en manos particulares, cobrando el Estado un fuerte impuesto de exportación. Pero no faltaba una corriente estatista, que reivindicaba para el Estado el manejo del negocio, prolongando el patrimonialismo fiscal heredado desde la época virreinal.

Pardo y su ministro de Hacienda Ignacio Elguera, en su doble propósito de crear rentas para salvar la bancarrota fiscal y en su deseo de limitar el consumo del salitre, intervino desde 1873 en los 
asuntos hasta entonces privados de la industria del nitrato. Con calma estudió la cuestión, y convencido de la imposibilidad de contemporizar con uno y con otro abono, favoreció al guano con detrimento del salitre, el cual fue objeto del Estanco del Salitre. Solo el Estado quedaba autorizado a comercializar el producto, quedando los particulares obligados a venderle su producción. En 1875, se radicalizó la política y se procedió a ordenar la expropiación de las oficinas salitreras. El pragmatismo fue más fuerte que sus convicciones liberales, pero lo único que le faltó al Perú para hacer funcionar plenamente su política salitrera fue tener soberanía territorial sobre las salitreras, ya que existía la competencia del salitre boliviano, explotado por capitales chilenos e ingleses.

Esta competencia terminó por sentar las bases de la Guerra del Pacífico en 1879, precipitada por un conflicto entre el gobierno boliviano y una empresa salitrera de capitales chilenos; el Perú se vio envuelto en el trance debido a un Tratado Secreto de Alianza firmado en 1873 bajo el gobierno civilista. Este tratado, secreto sólo de nombre, firmado a propuesta del gobierno boliviano, $y$ en cuyo diseño original se contemplaba la adhesión de Argentina (que al final se frustraría por las disputas argentino-bolivianas por la zona de Tarija), sirvió de pretexto al gobierno chileno para declarar la guerra al Perú. Este tema siempre ha sido, y es probable que siga siendo, materia de debate en torno de que si el gobierno de Manuel Pardo hizo lo correcto al aceptar la alianza boliviana. Sin duda la situación económica le imposibilitó la adquisición de material bélico, y lo condicionó a cimentar la seguridad nacional en base a un juego de alianzas, que como se vería trágicamente, fue sumamente imperfecto.

\section{EPÍLOGO}

\footnotetext{
${ }^{10}$ Habría que mencionar el canallesco editorial del periódico pierolista "La Patria", redactado por Pedro José Calderón, el 2 de septiembre de 1878, fecha del arribo de Pardo al Callao. Este editorial concluía con una abierta invitación al asesinato
}

"A pesar de todo lo que pueda decirse, Pardo hizo una intensa obra de estadista [...]. Estuvo en el poder solamente cuatro años $y$ en las más desfavorables condiciones hacendarias y económicas $y$ dentro de incesantes zozobras políticas. No fue el gobernante intuitivo o instintivo, ni el dictador omnímodo que delega su poder en ministros capaces. Llevó a la dirección del país una visión personal, culta, reflexiva y consciente y ejercitó una acción propia, susceptible de aplauso o de crítica; pero, en todo caso, impregnada de energía, audacia, voluntad de acierto, integridad y buena fe" (Basadre, 2005, p. 192).

Pero los odios hacia Pardo no se detuvieron con la entrega del mando en agosto de 1876 . A los pocos días, una turba estuvo a punto de asaltar la residencia de Pardo, y a los pocos meses, debió salir al exilio en Chile, del que retornó en 1878 , como Presidente del Senado. Pese a que sus familiares le aconsejaron no retornase al Perú por un tiempo, Pardo consideró que era su deber regresar. Desde su llegada, se pudo apreciar el encono de sus enemigos, en feroces andanadas que incitaban al crimen ${ }^{10}$, como parte de una praxis política en base a la eliminación del enemigo, que influyeron en Melchor Montoya, un oscuro sargento del batallón Pichincha para cometer uno de los crímenes más abominables de la historia peruana.

La tarde del sábado 16 de noviembre de 1878 , Pardo ingresó al Senado. La guardia le presentó armas, y al darse la voz de descanso, el sargento disparó por la espalda contra el ex presidente. Así, la carrera de un auténtico visionario de la política peruana se vio truncada por quienes se resistían a la necesaria reestructuración de las condiciones institucionales y económicas del Perú en crisis (Quiroz, 2013).

Cuando el cortejo volvió del cementerio, de enterrar el cadáver de Manuel Pardo, quizá el país

al citar una de las catilinarias de Cicerón, que al pie de la letra dice: "Yo te mataré al fin, pero lo haré cuando ninguna boca honrada deje de aprobar y aplaudir tu muerte". 
no supo que muy pronto asistiría a otro entierro más doloroso y terrible: el de las esperanzas de constituirnos en una nación pujante $y$ verdaderamente soberana. Siendo el Perú el país del "aquí no pasa nada" y del "Dios es peruano", costumbre resignada y estéril, que no tiene fundamento ni reafirmación de propósito, nos sorprendió la guerra en el desconcierto y la impotencia (Miró Quesada, 1961, p. 111).

\section{Bibliografía}

Basadre, J. (2005). Historia de la República del Perú (1822-1933). Lima, Perú: Empresa Editora El Comercio 9na. ed.

Cayo, P. (2004). Enciclopedia Temática del Perú. Tomo III: República. Lima, Perú: Empresa Editora El Comercio.

Contreras, C.; CUETO, M. (2013). Historia del Perú Contemporáneo. Lima, Perú: Instituto de Estudios Peruanos 5ta. ed.

Dávalos; Lissón, P. (1919-1926). La primera centuria: causas geográficas, políticas y económicas que han detenido el progreso moral y material del Perú en el primer siglo de su vida independiente. Lima, Perú: Librería e Imprenta Gil.

Del Busto Duthurburu, J. A. (1994). (director). Historia General del Perú. Lima, Perú: Editorial Brasa.

Espinosa, A. (2013). Siembra, convicción y peripecia: el socialcristianismo en el Perú (1532-2010). Lima, Perú: Fondo Editorial del Congreso del Perú.

González, M. (1938). Figuras y figurones. Manuel Pardo - Piérola - Romaña - José Pardo. París, Francia:Tipografía de Louis Bellenand et Fils.

Hampe, T. (2000). (coordinador). Historia del Perú. Lima, Perú: Lexus Editores.
Hunt, S. (2011). La formación de la economía peruana. Lima, Perú: Banco Central de Rerserva del Perú - Instituto de Estudios Peruanos - Pontificia Universidad Católica del Perú.

Karno, H. L. (1970). Augusto B. Leguía. The Oligarchy and the Modernization of Peru 1870-1930. Los Ángeles, Estados Unidos: Tesis de Doctorado, Universidad de California.

Klarén, P. F. (2004). Nación y sociedad en la historia del Perú. Lima, Perú: Instituto de Estudios Peruanos.

Larson, B. (2002). Indígenas, élites y Estado en la formación de las repúblicas andinas. Lima, Perú: Instituto de Estudios Peruanos Pontificia Universidad Católica del Perú.

López, J. (1947). Manuel Pardo. Lima, Perú: Librería e Imprenta Gil S. A.

Mc evoy, C. (2004). (compilación). La huella republicana liberal en el Perú. Manuel Pardo. Escritos fundamentales. Lima, Perú: Fondo Editorial del Congreso del Perú.

Mc evoy, C. (2007). Homo politicus. Manuel Pardo, la política peruana y sus dilemas 18711878. Lima, Perú: Oficina Nacional de Procesos Electorales - Instituto Riva-Agüero - Instituto de Estudios Peruanos.

Mc Evoy, C. (2016). La utopía republicana: ideales y realidades en la formación de la cultura política peruana 1871-1919. Lima, Perú: Fondo Editorial de la Pontificia Universidad Católica del Perú.

Mc Evoy, C. (1994). Un proyecto nacional en el siglo XIX. Manuel Pardo y su visión del Perú. Lima, Perú: Fondo Editorial de la Pontificia Universidad Católica del Perú. 
Miró Quesada, C. (1961). Autopsia de los Partidos Políticos. Lima, Perú: Ediciones Páginas Peruanas.

Mücke, U. (2010). Política y burguesía en el Perú: El Partido Civil antes de la Guerra con Chile. Lima, Perú: Institut Français d'Études Andines.

Paniagua, V. (2009). Manuel Pardo y el Partido Civil. Apogeo y crisis del primer partido político en el Perú. Lima, Perú: Fondo Editorial del Congreso del Perú.

Perú Ministerio de Gobierno. (1878). El asesinato de Manuel Pardo, Presidente del Senado. 16 de noviembre de 1878. Lima, Perú: Imprenta del Estado.

Pike, F. B. (1 969). The Modern History of Peru. New York, Estados Unidos: Frederick A. Praeger Publishers.

Quiroz, A. W. (2013). Historia de la Corrupción en el Perú. Lima, Perú: Instituto de Estudios Peruanos.
Ramos, C. (2002). Historia del derecho civil peruano. Siglos XIX y XX. Tomo III. Los jurisconsultos: El Murciélago y Francisco García Calderón. Lima, Perú: Fondo Editorial de la Pontificia Universidad Católica del Perú.

Sobrevilla, N. (2013). La ciudadanía corporativa. Política, constituciones y sufragio en el Perú (1821-1896). Lima, Perú: Instituto de Estudios Peruanos.

Tauro del, A. (2001). Enciclopedia ilustrada del Perú. Lima, Perú: PEISA.

Tocqueville, A. (2007). de. La democracia en América. Madrid, España. Ediciones Akal.

Villarán, L. F. (2016). La constitución peruana comentada. Lima, Perú: Centro de Estudios Constitucionales del Tribunal Constitucional del Perú.

Yepes del Castillo, E. (1981) Perú 1820-1920. ¿Un siglo de desarrollo capitalista?. Lima, Perú: Ediciones Signo. 